\title{
Study on the Influence of Mothers' Quality on Children's Development
}

\author{
Tingpimei Zhang \\ Zhongnan University of Economics and Law \\ Wuhan, China
}

\begin{abstract}
China's next-stage demographic dividend needs to be stimulated by the use of population quality and population structure. Therefore, the quality of the population of future generations is crucial to promoting social and economic development. By combing the literature, this paper finds that the quality of the mother, especially the cultural quality, has a positive impact on the development of the child. Therefore, it is necessary to pay more attention to increasing the investment in education for women and mothers.
\end{abstract}

Keywords-mother's quality; child's quality; demographic dividend

\section{INTRODUCTION}

China's economic development has been in good shape in recent years, benefiting from China's demographic dividend period. Behind the rapid economic development, the problems caused by the imbalance of population have become increasingly prominent: the population base is large, the population is growing too fast, the gender structure of the birth population is unbalanced, and the problem of aging is serious. These issues pose challenges to the development of the demographic dividend. In order to break through this bottleneck, it will be necessary to start to explore the development potential from the aspects of population structure and population quality. At present, how to optimize the population structure and improve the quality of the population is the focus of China's population policy. The good development of China's future generation population is the foothold of population policy, which puts urgent new requirements for future children. The development of children is first and foremost dependent on the family, mainly the upbringing and education of parents. Therefore, this paper focuses on the impact of maternal cultural literacy on the quantity and quality structure of children, education and health, and the importance of maternal quality to the development of children, and then proposes corresponding countermeasures and recommendations.

\section{THE PROBLEM OF POPULATION ISSUES FOR FUTURE GENERATIONS}

The three-dimensional demographic dividend theory points out that (Yang Yunyan et al., 2014), for a long time in the past, academic research on the relationship between population and economic growth focused on changes in total population or changes in the total labor force. They considered abundant labor resource reserves are crucial to realizing the miracle of China's economic growth. However, according to data released by the National Bureau of Statistics, in 2012, the 15-59-year-old working-age population in China showed an absolute decline for the first time in a long period of time. Simply relying on the labor force to prolong the demographic dividend is no longer feasible. It is necessary to start with the demographic structure and population quality, that is, the optimization of the population structure of the future generation of China and the improvement of the population quality. This means that future generations will face enormous challenges from population issues.

First of all, there is a serious imbalance in the sex ratio of Chinese population. In the absence of human interference, the sex ratio at birth is relatively stable, ranging from 103 to 107. After the 1980s in China, the sex ratio at birth has been continuously rising and high. The results of the "The Sixth National Census" show that the sex ratio of the birth population in China has reached 118.06. In China, the problem of high sex ratio at birth has spread from east and central to southwest and northwest, from provinces with agricultural population to large cities (Yang Fan, 2014), so that in the early 21 st century the sex ratio structure at birth of most provinces has been seriously out of balance. The high sex ratio at birth has become a common phenomenon and a national problem; on the international scale, China is also one of the countries with the highest sex ratio at birth. Whether it is for women in disadvantage or men with more population, gender imbalance will affect the normal evolution of their individual life processes, thus impacting traditional family functions and endangering population security, economic security, and social security in society as a whole. (Yang Juhua et al., 2009). Therefore, the problem of high sex ratio at birth can not to be underestimated, and it is also an important problem that China needs to solve urgently.

Second, the quality of Chinese population needs to be further improved. In terms of physical fitness, since the 1980s, with the development of social economy and medical level, China's population life expectancy has been generally extended, but it still faces the current health risks that medical care can maintain life but unable to cure diseases or eliminate disabilities. Infants and young children are the "susceptible" of this risk, and the incidence of new birth defects in China is $4 \%$ to $6 \%$ per year. Most of the pre-natal deficiencies were not found at birth (You Yunzhong, Zheng 
Xiaoying, 2005), reducing the health reserves of the offspring. In terms of cultural quality, although the cultural quality of China's population has been greatly improved, there is still a big gap compared with other developed countries. Due to the uneven distribution of educational resources, the historical problems left by the inequality between men and women in China, etc., the quality of education in different regions is intermingled, and the differences in personal cultural quality are obvious. And this difference will also have a direct impact on the next generation through intergenerational transmission.

In response to the above-mentioned population problem, it will also be necessary to make great efforts to improve the health rate and improve the quality of the population of the next generation on the basis of balancing the sex ratio at birth and maintaining a low birth rate, especially raising a higher demand for the future generation to raise the responsibility of raising families

\section{THE INFLUENCE OF MOTHERS' QUALITY ON FERTILITY WILLINGNESS AND BEHAVIOR}

Fertility behavior is not only constrained by various objective factors, such as social economic level, birth policy, family income, personal age, education level, and so on, but also influenced by family subjective factors, which refer to the concept of childbearing that is subject to subjective consciousness, including fertility needs, fertility motivation, and fertility willingness (Lu Jiehua et al., 2005). Among them, the mother's educational level will act on their fertility willingness, which will affect the substitution of the children's quantity and quality. According to Becker's theory of quantity and quality substitution for children, children are durable consumer goods produced by the family, so parents are the primary consideration of the study. As a direct responsibility for the child's investment and development in a family, the mother is responsible for the healthy development of the future of mankind. Studies have shown (Donald J. Hernandez \& Jeffrey S. Napierala, 2014) that the quality of the mother has a significant impact on the quantity and quality of the children.

The higher the education level of women, the higher the average age of first marriage, which leads to a lower fertility rate, and the more they actively accept the national family planning policy, the scientific knowledge of "prenatal and postnatal care", thus greatly reducing the mortality rate of newborns, reducing the incidence of congenital diseases and hereditary diseases and improving the physical fitness of children (Li Yadong, Xu Yanping, 2001). Compared with families with many children, the one-child family and the two-child family are more conducive to the quality of the child. The larger the family size, the more unfavorable the quality of the child (Wang Fang, Zhou Xing, 2012). With the development of the times, with the higher the level of education of women born in the 1970s and 1980s, the willingness to give birth to boys is gradually weakening, and gender-free preferences are gradually forming (Li Boping, Xiang Huan, 2010). In other words, the improvement of women's education level is not only conducive to optimizing the quantity and quality structure of children, but also helps to balance the sex ratio at birth.

\section{THE INFLUENCE OF MOTHERS' QUALITY ON CHILDREN'S CULTIVATION}

First, the mothers' health and lifestyle determines the children's health (Anna Yevgen'evna Kononova, 2018). Mothers can prevent childhood obesity by learning about nutrition (Adam P Knowlden \& Eric Conrad, 2018). In addition to hereditary factors, mothers' education can have a positive impact on the children's height (Duncan Thomas \& et al, 1991). The higher the mothers' education, the higher the children's height.

Second, the quality of the mothers can have a major impact on the children's education (Benta A. Abuya \& et al, 2018). Children of parents with higher education are more capable in learning than other children, and the improvement of mothers' education is more effective in improving children's learning ability (Ng, Florrie Fei-Yin \& et al, 2019). A mother with a high level of education can create a harmonious family atmosphere, which is conducive to the development of children's good learning behavior and helps to improve their language and literacy skills (Katherine Magnuson \& Hilary Shager, 2008). Moreover, the beneficial influence of parents' educational level on children is not limited to academic achievements in schools, better educational resources, higher education, etc., but also extends this positive influence to the future occupations and socioeconomic status of children. (Wang Fang, Zhou Xing, 2012). In addition to the mothers' level of education, the quality of the mothers' postpartum will also have a positive effect on the children's education. Mothers involved in basic adult education can significantly improve their children's pre-school performance and pass on good qualities and values to the next generation (Katherine Magnuson \& Hilary Shager, 2008).

\section{THE CURRENT SITUATION OF WOMEN'S QUALITY IN CHINA}

Because of the history of $90 \%$ illiteracy among the old Chinese women and the long-term influence of the feudal concept of "women's incompetence is virtue" in Chinese traditional culture, it has caused the historical debt of the weak female education foundation in China. In the past few decades, under the impact of compulsory education and the enlightenment of concept, China has made great achievements in popularizing education and improving attainment. However, compared with advanced countries, China's female higher education is still far behind.

The lack of basic education for women deeply affects the "learning and education" of women after becoming mothers. This article mentions that mothers' "learning and education" is an enriching process for the overall quality of the mothers, and it plays a vital role in how to raise and nurture the children in the future. Mothers' "education" has a positive impact on children, so it is also important for mothers to receive parenting training after childbirth. 
From the view of the mothers themselves, due to their lack of basic education, their willingness to accept their mothers' teaching is low and their motivation is insufficient. The weak basic education as well as the lack of parenting knowledge makes the mothers' overall quality in addition to the cultural level is still not high, forming a short family education in family, school and social three-dimensional education of the children, which will inevitably have a certain hindrance to the healthy development of children in the future.

From a social point of view, with the improvement of education and quality of life, children's role of pension and family security has greatly decreased. Some young women with high education, high positions and high income in China think that raising children is a burden, and even choose not to have children. However, in Chinese society, many families still adhere to the "female only have the responsibility of raising children", which is undoubtedly a certain mental pressure for modern new women, resulting in an embarrassing situation that although the sex ratio is still high, many highly educated women are "difficult to get married". One of the reasons for this social phenomenon is that society creates contradictions in the social status and social value of women in China. In the socialist society, the relationship between men and women has achieved equality in law, but the gap formed in history cannot be adjusted in place by legal provisions. Although the social status of women in China has gradually increased and the right to education is relatively equal, because the whole society neglects the spiritual modernization and quality of the people, the society still discriminates against women who have the fertility ability. As a result, the family value of the mothers is always higher than the social value. Furthermore, the surveys show that boys can get one position on average 2 or 3 times, and girls need 8 to 10 times on average. Although they have the same qualities as men, their social values haven't been recognized. Therefore, the society urgently needs a social system in which women participate in, that is, let the society recognize the labor value of the mothers and honor their labor value. Of course, this is not a one-step process. It is a long-term and arduous task.

\section{CONCLUSION AND COUNTERMEASURES}

In summary, the quality of the mothers, especially the cultural literacy of the mothers, is vital to the development of the children. Therefore, improving the quality of the mothers is a very important task.

This paper puts forward the following suggestions in combination with the actual situation:

The first is to increase the policy support of the "mothers' education" section in the current maternity supporting policy. Since 2004, China has raised the quality of mothers and the quality of children to the height of policy. Many provinces and cities across the country have established "mothers' education engineering" bases, and local governments have developed mothers' education based on their own characteristics and achieved remarkable results (Yang Junli, 2011). The "Mothers' Education Project" needs to be further launched across the country. Not only that, but also the policy of supporting mothers' education should be added to the family planning benefit-oriented policy. The combination of the two will stimulate the implementation of the "mothers' education project" with the family planning benefit-oriented policy, and promote the realization of family planning goals with "Mothers' Education Project" to achieve a long-term population balance. For now, this is just a good vision. The specific enforceability still requires long-term research and practice to draw conclusions.

The second is to use social organizations such as schools and communities to promote the social synergy of mothers' quality education and to promote the development of mothers' education. The school is an important educational place. It not only teaches children scientific knowledge, but also is a key part of the children's good outlook on life and world in the process of socialization. Parental participation is also crucial. It will also be of great significance to incorporate family education and maternal quality projects into the overall school education plan, such as the establishment of "parent school" and "mother school", and actively explore effective ways and methods of family quality education. In addition to schools, community organizations, women's federations and other social organizations can also be used to promote mother education as a specific and clear content in the process of community education, paying attention to poverty, single mothers, listening to their voices and wishes, and earnestly safeguarding their legitimate interests and requirements; It will be necessary to do a good job in quality education and family education, and carry out educational activities that are fun and educational. It will also be very important to cultivate and establish a group of "good mothers", so that every mother can realize her role responsibility and social responsibility.

The third is to use the mass media to promote mothers' education. It is important to use the combination of education and entertainment on the Internet to promote mothers' education, and help parents of the new era, especially fashionable young women, to establish a healthy and fashionable concept of parenting and good two generations of interaction. This is not only to teach mothers parenting knowledge, but also to use extensive media propaganda to gradually change the old concept of society to mothers and to establish a new look of "new society, new women, new mothers."

\section{REFERENCES}

[1] Yang Yunyan, Xiang Huali, Huang Ruiqin, "Selective Two-child" Policy and the Demographic Dividend of Hubei Province [J] Journal of Zhongnan University of Economics and Law, 2014, 05: $3-8+13$ +158 . (in Chinese)

[2] Yang Fan, The Relationship of High Sex Ratio at Birth and Demographic Transition in China: A Modernization Perspective [J] Population \& Economics, 2014, 05: 23 - 32. (in Chinese)

[3] Yang Juhua, Song Yueping, Zhai Zhenwu, Chen Wei, Fertility Policy and Sex Ratio at Birth [M] Beijing: Social Sciences Academic Press (China). 2009. 11. (in Chinese) 
[4] You Yunzhong, Zheng Xiaoying, Mortality and Health of the Chinese Population Levels, Patterns, Causes and Trends Since the 1980s [M] Beijing: Peking University Press, 2005, 3. (in Chinese)

[5] Lu Zhihua, Fu Chonghui, Zhang Jinhui, Zeng Xuchun. Fertility Behavior of the Migrant Women in Shenzhen City: An Analysis Using Structural Eqaution Models [J] Population Research, 2005, 02: 25 - $33+96$. (in Chinese)

[6] Donald J. Hernandez\&Jeffrey S. Napierala. Mother's Education and Children's Outcomes: How Dual-Generation Programs Offer Increased Opportunities for America's Families [J]. Disparities Among America's Children NO. TWO, 2014.7.

[7] Li Yadong, Xu Yanping, Women's Educational Level and the Population's Quality [J] Tsinghua Journal of Education, 2001, 01: 50 $55+97$. (in Chinese)

[8] Wang Fang, Zhou Xing, The Tradeoff Between Child Quality and Child Quantity in China: Use Quantile Regression Analysis [J] Northwest Population Journal, 2012, 03: $12-16+22$. (in Chinese)

[9] Li Boping, Xiang Huali, The Empirical Study on the Pregnancy Intention of Childbearing Age Woman from Different Generation and Its Influencing Factors: Evidence from Wuhan Megalopolis [J] Population \& Economics, 2010, 03: 13 - 20. (in Chinese)

[10] Anna Yevgen'evna Kononova.The Socio-Economic Factors of Children's Health in Russia[J].Russian Social Science Review.2018,Vol.59(No.2): 113-126.

[11] Knowlden, Adam P.;Conrad, Eric.Two-Year Outcomes of the Enabling Mothers to Prevent Pediatric Obesity through Web-Based Education and Reciprocal Determinism (EMPOWER) Randomized Control Trial [J]. HEALTH EDUCATION \& BEHAVIOR HEALTH EDUCATION \& BEHAVIOR.2018, Vol.45(No.2): 262-276.

[12] Benta A. Abuya; Joyce Mumah; Karen Austrian; Maurice Mutisya; Caroline Kabiru.Mothers' Education and Girls' Achievement in Kibera: The Link With Self-Efficacy [J]. SAGE Open. 2018,Vol.8(No.1)

[13] Ng, Florrie Fei-Yin; Pomerantz, Eva M.; Lam, Shui-fong; Deng, Ciping; Ng, Florrie Fei-Yin; Lam, Shui-Fong. The Role of Mothers' Child-Based Worth in Their Affective Responses to Children's Performance. [J]. Child Development. 2019,Vol.90 (No.1): e165e181.

[14] Duncan Thomas\&John Strauss \&Maria-Helena Henriques. How Does Mother's Education Affect Child Height? [J]. The Journal of Human Resources, Vol. 26, No. 2 (Spring, 1991), pp.183-211

[15] Katherine Magnuson \& Hilary Shager. The Effects of Increased Maternal Education on Children's Academic Outcomes: Evidence from the ECLS-K [J]. ITP Spring Training Seminar, 2008.4.11.

[16] Yang Junli, Research and Practice of "Mothers' Education Project" Taking Karamay as an Example [J] Journal of Karamay, 2011, 03: 66 - 71. (in Chinese) 